\title{
Measurement of Light Rare Earth Element of Samarium in the Processing of Mineral Concentrate Samples by HLLME Pre-Concentration Method and ICP-MS
}

\author{
Alireza.Dehghan ${ }^{1, *}$, Mohammad Rezaee ${ }^{2}$, Somayeh Veyseh ${ }^{3}$ and Shabnam Najafi AsliPashaki ${ }^{4}$ \\ 1 Department of Research and Development, Applied research center of the geological survey of Iran, Alborz, \\ Iran \\ 2 Nuclear Fuel Cycle Research School, Nuclear Science \& Technology Research Institute, Atomic Energy \\ Organization of Iran \\ 3 Department of Research and Development, Applied research center of the geological survey of Iran, Alborz, \\ Iran \\ 4 Department of Research and Development, Applied research center of the geological survey of Iran, Alborz, \\ Iran \\ * Correspondence: alirezadehghan364021@gmail.com;
}

Received: Sep 14, 2020; Accepted: date; Published: date

\begin{abstract}
In this study, a method based on floatation assistance of homogeneous liquid-liquid microextraction (FA-HLLME) combined with inductively coupled plasma-mass spectroscopy (ICP-MS) was proposed for the measurement of trace Samarium in Mineral concentrate samples. As one of the miniaturized separation and extraction techniques, homogenous liquid-liquid microextraction (HLLME) has been widely applied in the field of Mineral processing. PAN (1-(2-Pyridylazo)-2-naphthol) was used as the complexing agent and 1-Dodecanol and Acetone was selected as extraction and homogeneous solvents, respectively. The factors that influenced the extraction efficiency for Samarium measurement (including $\mathrm{pH}$, extraction, and homogeneous solvents, concentration of $\mathrm{PAN}$ and $\mathrm{NaCl}$, extraction time) were studied statistically. Under the optimum conditions ( $\mathrm{pH}=8.0,140 \mu \mathrm{L}$ 1-Dodecanol, $1.2 \mathrm{~mL}$ Tetrahydrofuran, $3.045 \times 10^{-4} \mathrm{~mol} \mathrm{~L}^{-1} \mathrm{PAN}$, $2.5 \mathrm{~mol} \mathrm{~L}^{-1} \mathrm{NaCl}$, and $120 \mathrm{sec}$ of extraction time), the linear dynamic range for Samarium determination was $10.0-220.0 \mathrm{ng} \mathrm{L}^{-1}\left(\mathrm{R}^{2}=0.9862\right)$ with a limit of detection (LOD) for Samarium was $2.91 \mathrm{ng} \mathrm{L}^{-1}$. The relative standard deviation (R.S.D.) $\left(\mathrm{C}=40 \mathrm{ng} \mathrm{L}^{-1}, \mathrm{n}=7\right)$ was $2.1 \%$ and the enrichment factor of 250 for Samarium extraction. The proposed method was successfully applied to the measurement of Samarium in different Mineral concentrate samples.
\end{abstract}

Keywords: Samarium; measurement; HLLME; Mineral samples; ICP-MS

\section{Introduction}

Samarium is an element with atomic number 62, and was discovered by Paul-Émile in 1879 in France. Its name is derived from samarskite (a mineral) [1,2]. This element was detected through spectroscopy because of its sharp absorption lines. Paul-Émile discovered this element from the mineral samarskite which was named in the honour of Colonel Samaraski (a Russian Mine official) [3]. The physical and chemical properties of samarium is including: Atomic Number $=62$, Oxidation States $=+2$ and +3 , Atomic Radius $=180$, Atomic Mass $=$ Atomic Mass, Boiling Point $(K)=2064$, Melting Point $(K)=1350$, Density $=7520$ and Ionic Radius $=96$. 
Samarium is a rare earth metal with a bright silver luster, and is reasonably stable in the air [4]. Samarium is never found free in nature but like other rare earth elements contains various minerals such as bastnasite, monazite, and samarskite. Bastnasite and monazite are used as commercial resources. In recent years, samarium is obtained through ion exchange processes, liquid extraction techniques, and electrochemistry. However, mischmetal contains $1 \%$ samarium. Samarium can also be obtained by reducing its oxide with lanthanum [5]. Compounds of samarium include fluorides in the forms of $\mathrm{SmF}_{2}$ and $\mathrm{SmF}_{3}$, chlorides in the forms of $\mathrm{SmCl}_{3}$ and $\mathrm{SmCl}_{2}$, bromides in the forms of $\mathrm{SmBr}_{2}$ and $\mathrm{SmBr}_{3}$, iodides in the forms of $\mathrm{SmI}_{2}$ and $\mathrm{SmI}_{3}$, oxides in the form of $\mathrm{Sm}_{2} \mathrm{O}_{3}$, sulfides in the form of $\mathrm{Sm}_{2} \mathrm{~S}_{3}$, selenides in the form of $\mathrm{Sm}_{2} \mathrm{Se}_{3}$, and tellurides in the form of $\mathrm{Sm}_{2} \mathrm{Te}_{3}$ [6].

Samarium is a fairly hard, pale silvery white metal. Samarium has 30 known isotopes and the stable isotopes include ${ }^{144} \mathrm{Sm},{ }^{150} \mathrm{Sm},{ }^{152} \mathrm{Sm}$ and ${ }^{154} \mathrm{Sm}$. The element ${ }^{152} \mathrm{Sm}$ is the most abundant isotope with $26.75 \%$ natural abundance. The element ${ }^{148} \mathrm{Sm}$ is extremely long-lived radioisotopes with half-life of $7 \times 10^{15} \mathrm{yr}$. The naturally occurring element ${ }^{146} \mathrm{Sm}$ is also fairly long-lived radioisotopes with half-life of $1.03 \times 10^{8} \mathrm{yr}$. The long lived isotopes, ${ }^{146} \mathrm{Sm}$ and ${ }^{148} \mathrm{Sm}$ are primarily decayed by alpha decay to isotopes of neodymium $[7,8]$.

Samarium has no significant biological role but it is said that it can stimulate metabolism. Presence of samarium at the workplace is dangerous due to the fact that its gases can be inhaled with air and this can cause obstructive pulmonary disease especially during long-term exposures. In addition, samarium can cause cancer in human body and being exposed to it can increase the risk of cancer. Eventually, it can be a threat for the liver when it accumulates in the human body [9]. Samarium spreads in the environment in different ways significantly through oil production industries. Moreover, when household appliances are thrown away, samarium enters the environment. Afterwards, it gradually accumulates in the earth, and it will eventually lead to increasing concentration of samarium in the human body, animals, and particles of the soil. In water animals samarium can cause damage to cell membranes, and consequently having negative effects on the function of reproduction and nervous system [10].

Samarium is one of the rare chemical elements that is used in household devices like colour televisions, glass, and fluorescent \& energy-saving lamps. All rare chemical elements have nearly similar properties. Samarium is very rare and too little of it exists in nature. Samarium is used for carbon arc lighting in motion pictures industry [11]. Samarium is used in the concentration process of the $\mathrm{CaF}_{2}$ crystals which are beneficial to the eye lasers [12,13]. Samarium can also be used in neutron absorbers of nuclear reactors [14]. Samarium is used in the production of alloys and headphones [15]. Moreover, Samarium cobalt magnets are being used to produce highly resistant permanent magnets with internal force of $2200 \mathrm{kA} / \mathrm{m}$ [16]. Samarium oxide is also effective in UV absorption of optical glasses [17]. Samarium compounds act as phosphorous sensitizers in UV [18]. Samarium oxide catalyst is used for dehydration and dehydrogenation of ethanol [19]. Due to the efficiency of samarium in catalysts production and glass polishing the usage of it is increasing.

Inductively Coupled Plasma Mass Spectrometry (ICP-MS) is a practical method for samarium measurement, and has recently received significant attention $[20,21]$. However, in particular conditions the direct analysis of Mineral concentrate samples based on this method is a little difficult due to the low density of this element with the presence of irritable ions. One of the solutions to this problem is performing a sample preconcentration via separation techniques and then reading the results by using different instruments. Preconcentration process involves a set of various processes to increase the ratio of the influential factor to the other elements in the solvent. Preconcentration process will improve the limit of detection, sensitivity, and accuracy of the analysis. This survey is basically concerning the preconcentration of samarium based on homogenous liquid-liquid microextraction technique [22,23].

Up to now, a variety of extraction methods have been employed by using efficient instruments. To mention some of these methods, we can name solid phase extraction, supercritical fluid extraction, salting-out extraction, liquid-liquid extraction and etc. liquid-liquid extraction method is defined as the selective transfer of one or more substance from a liquid (usually water) to another immiscible liquid (usually organic phase) which is the most common method for extraction and 
preparation of the environmental and mineral samples. Although this method is highly-efficient and sensitive, some of its drawbacks include requiring overuse of organic solvent and large volumes of sample, also the possibility of emulsion formation and being time-consuming. Thus, the liquid phase microextraction technique is being used which is the miniature version of the usual liquid-liquid extraction. For this study, the volume of the extractant solvent has been minimized largely to microliter levels. To mention some of the liquid phase microextraction techniques, we can refer to single-drop microextration (SDME) [24], dispersive liquid-liquid microextraction (DLLME) [25], cloud-point microextraction (CPE) [26], hollow fiber liquid-phase microextraction (HF-LPME) [27], solidified floating organic drop microextraction (SFODME) [28], and homogeneous liquid-liquid microextraction. Homogeneous liquid-liquid microextraction was first used by Moretta et. al. in 1973 to extract Fe (II) as a complex [29]. Nowadays, this method is being widely used for studying the extraction of different compounds and elements which has also shown acceptable results. The method of homogeneous liquid-liquid extraction has been introduced in 2012 in order to be used in extraction and preconcentration process of the aromatic hydrocarbon compounds in environmental and mineral samples.

Haji Hosseini et al., have introduced a novel modality of liquid-liquid microextraction, referred as homogeneous liquid-liquid microextraction via flotation assistance (HLLME-FA) method. HLLME-FA similar to the DLLME and HLLE methods, a mixture of extraction and homogeneous solvents is injected into an aqueous sample to form in the initial state a homogeneous solution and then form an emulsion consisting of fine droplets of the extraction solvent, homogeneous solvent and water. Homogeneous solvent which causes the solubility of extraction solvent increases in water and finally the homogeneous solution was formed in the extraction cell and by using salt the separation of the two phases was happened. In this method, a special extraction cell was designed to facilitate collection of the low-density solvent extraction. No centrifugation was required in this procedure. By using air flotation, the organic solvent was collected at the conical part of the designed cell $[30,31]$.This method is easy to use, quick, and inexpensive, and additionally with high level of recovery strength and transcription factor.

Ligand PAN (1-(2-Pyridylazo)-2-naphthol) used in this study was red, in a solid state, soluble in methanol, with molecular weight of $249.27 \mathrm{~g} / \mathrm{mol}$ and $\mathrm{mp} 138-141\left({ }^{\circ} \mathrm{C}\right)$. PAN ligands are compounds with high polarity which have the capacity of being very highly-soluble. Moreover, PAN ligands can dissolve in many solvents without any limitation. This ligand dissolves in a wide range of solvents and thus, can be used widely. Solubility of this ligand shows that there is no limitation in the case of using polar solvents. To mention the main features of this ligand, one can refer to a very desirable formation of metal complex ions [32]. Degree of interaction can be controlled by $\mathrm{pH}$. However, ionic strength and charge of the metal ions can have some impact, too. Because these ligands will react to the metal ions in a very desirable way, they can be used as the chelating agents.

The present investigation has centered on the development of a reliable method for the measurement of samarium in of Mineral concentrate samples. We for the first time use the new preconcentration method of HLLME-FA, which is combined with ICP-MS for the measurement measurement of samarium in of Mineral concentrate samples. The most effective variables on the HLLME-FA method could be considered as type and volume of extraction solvent, ionic strength, type and volume of homogeneous solvent, $\mathrm{pH}$, concentration of ligand and time of extraction.

\section{Materials and Methods}

\subsection{Chemicals and Reagents}

The stock standard solution for Sm was prepared immediately before use, by stepwise dilution of $1000 \mu \mathrm{g} \mathrm{mL}^{-1} \mathrm{Sm}$ stock standard solution in $\mathrm{HNO}_{3} 0.5 \mathrm{~mol} \mathrm{~L}^{-1}$. N-hexane, n-heptane, toluene, 1-dodecanol, methanol, Tetrahydrofuran, acetone and ethanol were obtained from Merck (Darmstadt, Germany). PAN (1-(2-Pyridylazo)-2-naphthol) have been provided from Sigma-Aldrich company, $\mathrm{HNO}_{3}, \mathrm{HF}, \mathrm{HCLO}_{4}$, and $\mathrm{HCL}$ (High-purity acids) from Merck Suprapure, and sodium chloride (Nacl) from Merck as well. 


\subsection{Instruments}

Inductively coupled plasma mass spectrometry (ICP-MS) instrument Perkin Elmer Sciex ELAN 9000 model made in the USA with the following features was deployed for the analysis of the extracted amount of samarium. The instrumental optimal conditions selected as recommended by the manufacturer are summarized in Table 1. PH meter instrument JEN WAY 3510 model was used for adjusting the $\mathrm{pH}$. Youngling ultra pure water purification system (Aqua MaxTM-ultra, Korea) was used for purification of water.

Table 1. Optimal conditions of ICP-MS instrument for samarium ion measurement

ELAN 9000 Instrumental Conditions and Method Parameters

$$
\text { RF Power }
$$

Plasma Gas Flow

Auxiliary Gas Flow

Nebulizer Gas Flow

Solution Pump Rate

Sample Introduction System

Number of Replicates

Total Acquisition Time
1400 Watts

$14 \mathrm{~L} / \mathrm{min}$

$1 \mathrm{~L} / \mathrm{min}$

$0.7 \mathrm{~L} / \mathrm{min}$

$1.50 \mathrm{~mL} / \mathrm{min}$

Cross-flow with Scott spray chamber

3

$4: 16$ minutes

\subsection{Mineral Concentrate Sample Preparation and Performing the HLLME-FA Methods}

For preparation process, the samples will be passed through a 150 mesh. In the next step, all the obtained samples will be dried in a $60^{\circ} \mathrm{C}$ oven for 8 hours. In addition to the real mineral concentrate samples a standard sample and a blank sample will be taken, too (the blank is free from mineral concentrate and all the actions carried on the other samples will be done on this, too. For example, all the acids added to the mineral sample will be poured in this container, too.) Then from each sample $0.05 \mathrm{gr}$ will be weighed and poured in Teflon containers. On each sample a concentrated $\mathrm{HNO}_{3}$ will be added by a $8 \mathrm{cc}$ pipette and after that placing it on a $250{ }^{\circ} \mathrm{C}$ hotplate for $20 \mathrm{~min}$, then removing it from the hotplate and letting it cool down for $10 \mathrm{~min}$. Subsequently, HF will be poured on the samples with $14 \mathrm{cc}$ sampler, then $4 \mathrm{cc} \mathrm{HCLO}_{4}$ will be poured on the samples which was taken with a pipette. At that time, the samples will be placed on a $250{ }^{\circ} \mathrm{C}$ hotplate to be dissolved completely. After that 4cc $\mathrm{HCLO}_{4}$ will be added to the samples to let the HF be vaporized from the samples. Then $20 \mathrm{cc}$ ultra-water will be added to the samples and stirred for $10 \mathrm{~min}$, then, placed in $100{ }^{\circ} \mathrm{C}$ and subsequently increasing the volume of the samples in a $25 \mathrm{cc}$ Volumetric flask. Figure.1 shows the schematic procedure of the proposed method. A mixture of $1.2 \mathrm{~mL}$ THF (homogeneous solvent) and $140 \mu \mathrm{L}$ 1-Dodecanol (extraction solvent) were added to the home-designed extraction cell (Figure.1-a). $120 \mu \mathrm{L}$ PAN $(0.06 \mathrm{M}) 3.045 \times 10^{-4} \mathrm{~mol} \mathrm{~L}^{-1} \mathrm{PAN}$ as a ligand was added into the $25 \mathrm{~mL}$ saline aqueous solution and Mineral concentrate solution which $\mathrm{pH}$ was adjusted at 8 . This solution was injected into the extraction cell by syringe, rapidly (Figure.1-b). In this step, in the initial state of injection, a homogeneous solution was formed and then with the continuation of injection an emulsion consisting of fine droplets of the extraction solvent were formed (Figure.1-c). After about $120 \mathrm{sec}$, by using air flotation, the organic solvent was collected on the top of the solution (Figure.1-d). After separation of the two phases, a few volumes of distilled water were added into the glass tube on the side of the cell (Figure.1-e). The floated organic solvent was raised into the conical part of the cell. After evaporation of organic solvent, the residues was dissolved in the 0.5 mol L-1 $\mathrm{HNO}_{3}$ and was injected into the ICP-MS instrument 


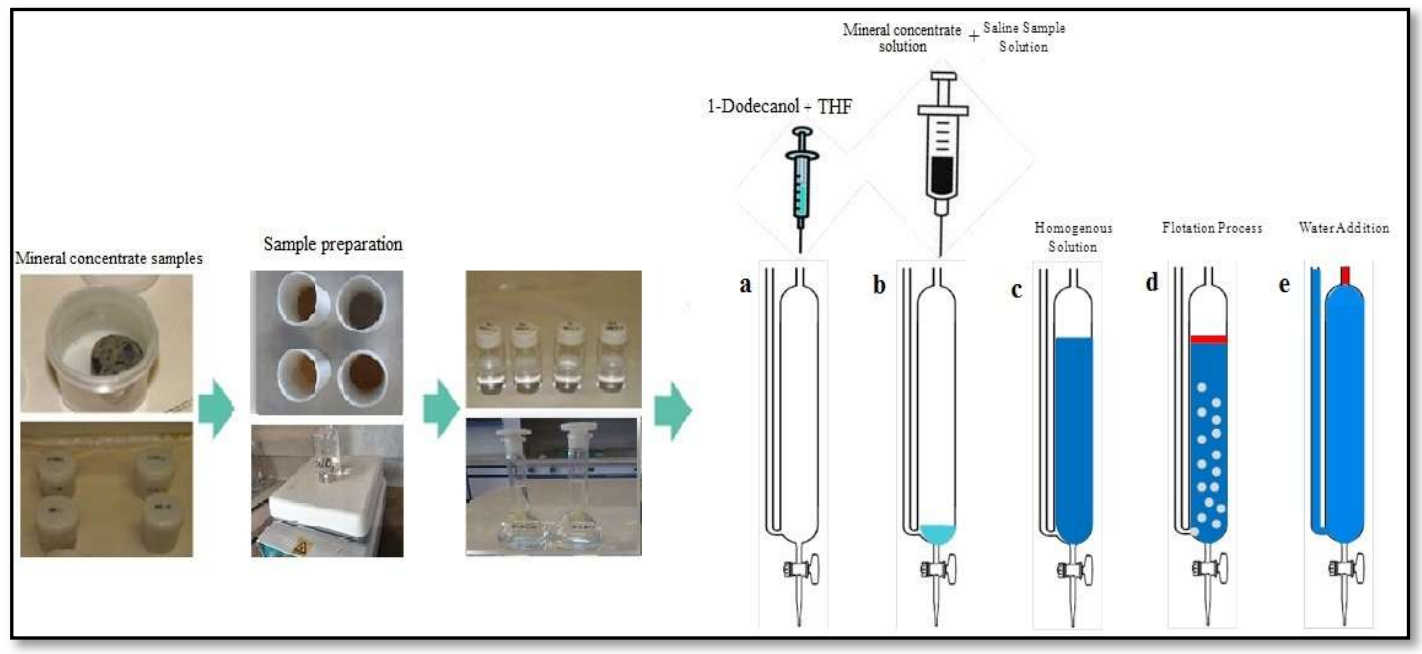

Figure 1. Schematic HLLME-FA procedure (Fig. 1-a) a mixture of $1.2 \mathrm{~mL}$ THF containing $140.0 \mu \mathrm{L}$ 1-Dodecanol was added to the home-designed microextraction cell, (Fig. 1-b) 25.0 mL of the saline aqueous solution saline aqueous solution and Mineral concentrate solution was added into the microextraction cell, (Fig. 1-c) a homogeneous solution was formed in the cell, (Fig. 1-d) using air flotation, organic solvent was moved to the top of the solution, (Fig. 1-e) a small volume of distilled water was added into the glass tube on the side of the cell.

\section{Results}

\subsection{Results and discussions}

HLLME-FA combined with ICP-MS was developed for determination of samarium in Mineral concentrate samples. In order to obtain a high recovery and enrichment factor, effects of different parameters such as the type and volume of the extraction and homogeneous solvents, $\mathrm{pH}$, concentration of ligand, salt amount and extraction time were optimized.

\subsection{Optimization}

\subsubsection{Selection of extraction solvent}

The selection of an extraction solvent is of great importance in solvent microextraction methods in order to obtain efficient extraction. In the selection of extraction solvent, some factors should be considered. The selection of a suitable extraction solvent is limited by several characteristics, they must have low water solubility, low density than water, be able to extract the analyte of interest and be compatible with the analytical instrumentation to be used. In current study, to investigate the applicability of the proposed method for determination of the target analyte, some solvents including: toluene, 1-Dodecanol, n-hexane and n-heptane were selected and optimized. It is necessary to add an excess amount of solvent to recover an equal volume of different extraction solvents in the upper layer for comparison. The results are provided in Fig. 2. As shown in Fig. 2, 1-Dodecanol showed the highest extraction efficiency. Thus, 1-Dodecanol was selected for subsequent experiments. 


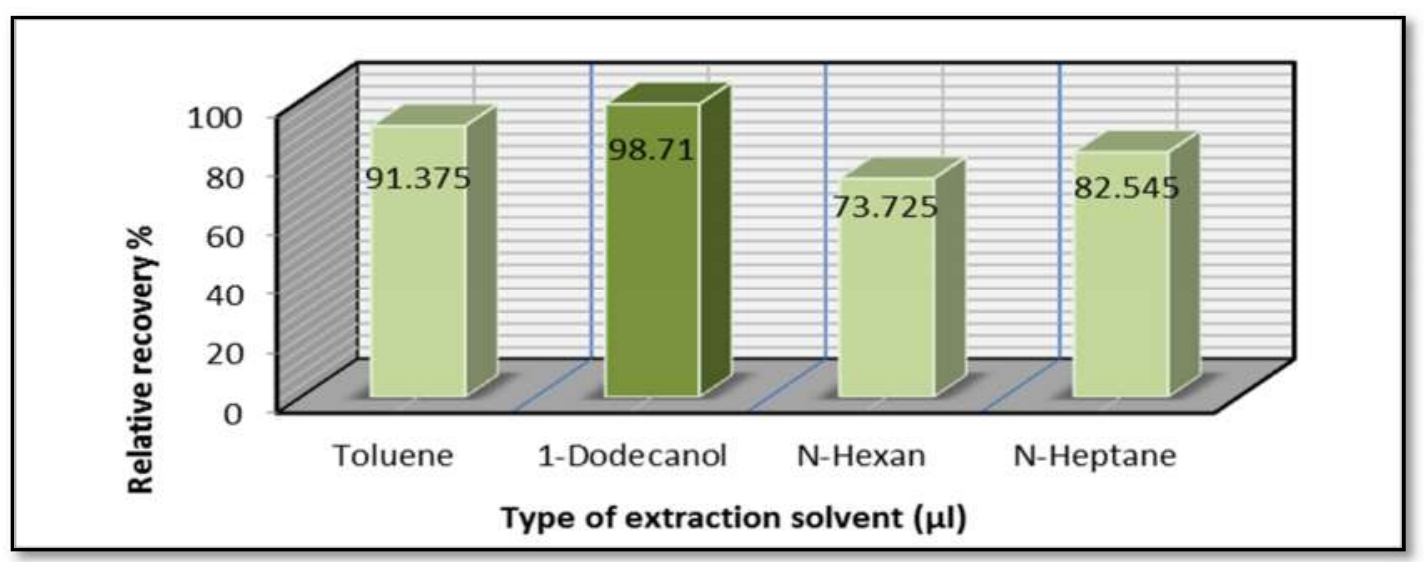

Figure 2. Effect of type of extraction solvent on the extraction efficiency

\subsubsection{Selection of homogeneous solvent type}

To select the appropriate homogenizer solvent, methanol, ethanol, aceton and tetrahydrofuran (THF) solvents were assessed. The dispersive solvent had to be miscible in organic phase (extractant solvent) and water phase (sample solution). Type of the dispersive solvent has impact on the viscosity of the injection phase and subsequently on the stability of the homogeneous solvent and recovery of the extraction. The results are provided in Fig. 3. As shown in Fig. 3, The best result has been shown by the use of tetrahydrofuran (THF). Thus, THF was selected for subsequent experiments.

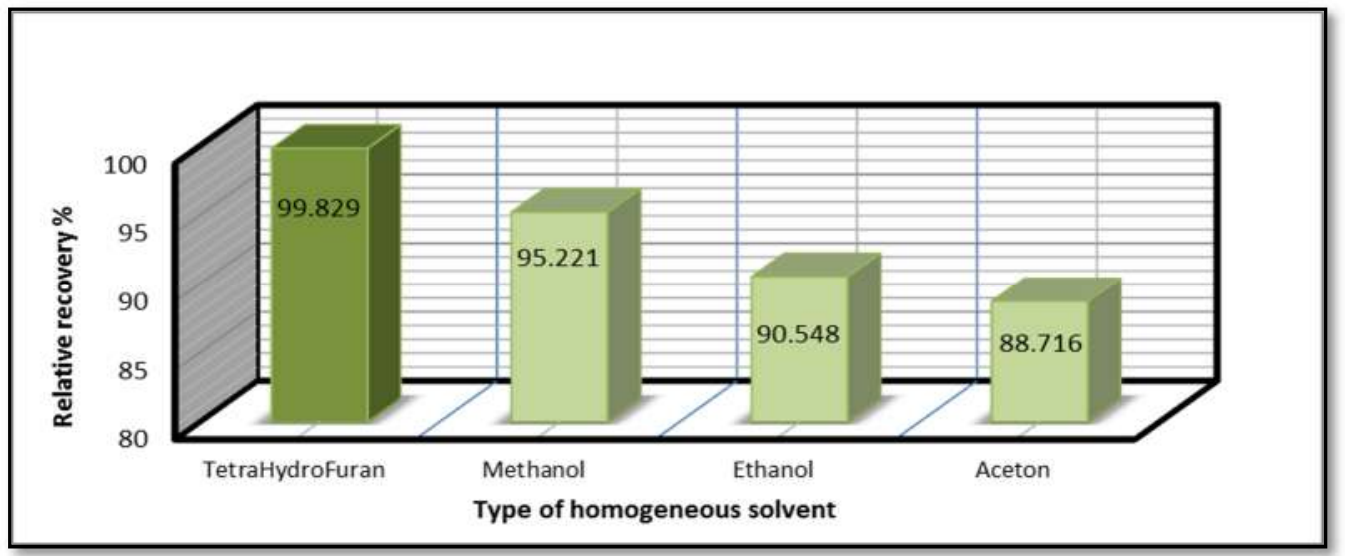

Figure 3. Effect of type of extraction solvent on the extraction efficiency

\subsubsection{Selection of extraction and homogeneous solvent volumes}

To examine the effect of extraction solvent volume, different amounts of 1-Dodecanol (80.0, 120.0, 140.0, 160.0, and 180.0 $\mu \mathrm{L}$ ) were evaluated. By increasing the volume of 1-Dodecanol, the extraction efficiency of the analyte decreased, owing to the increase in the volume of the collected organic solvent. Based on the experimental results (Fig. 4), 140.0 $\mu \mathrm{L}$ 1-Dodecanol was adopted for further experiments. 


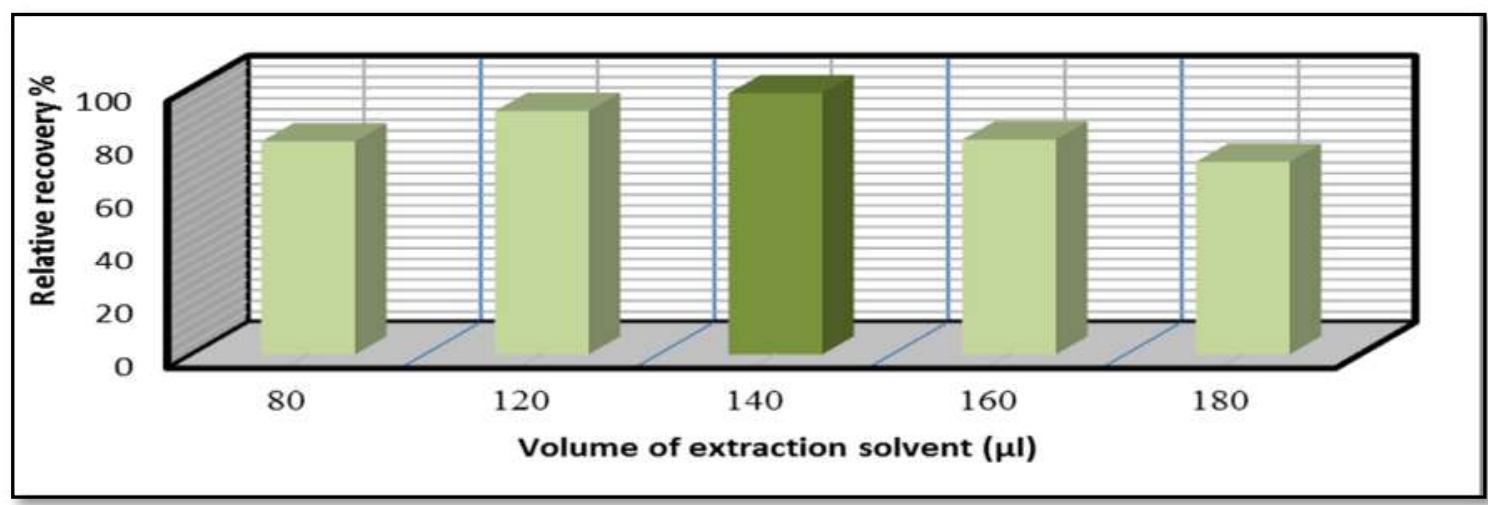

Figure 4. Effect of volume of extraction solvent on the extraction efficiency

In order to study the influence of the volume of homogeneous solvent on the extraction efficiency, different volumes of Tetrahydrofuran (0.5, 1.0, 1.25, 1.5, 1.75, 2.0, 2.25 and $2.5 \mathrm{~mL})$ was used. The results (Fig. 5) showed that with increasing of homogeneous solvent volume (THF), the extraction efficiency are decreased; that is because of the increasing lipophilic characteristic in aqueous sample solution and decreasing distribution constant. Thus, $1.25 \mathrm{~mL}$ THF was chosen in this work.

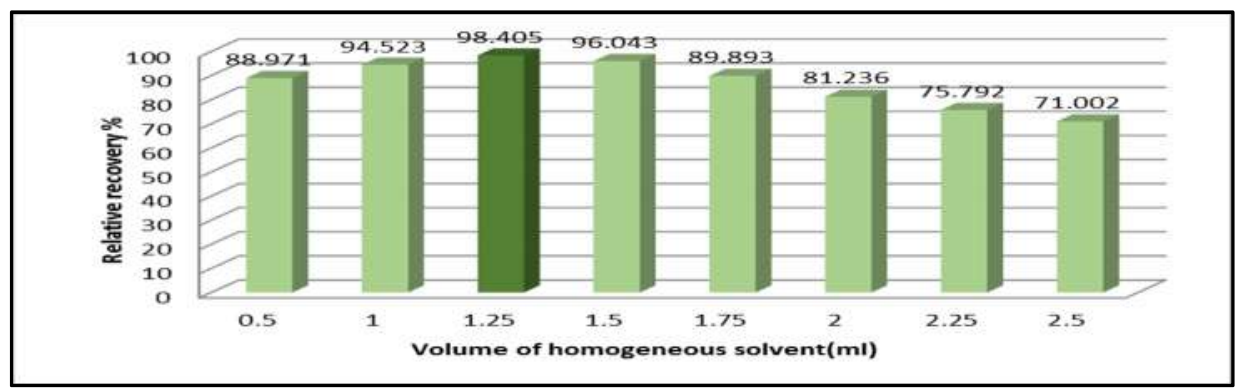

Figure 5. Effect of volume of homogeneous solvent on the extraction efficiency

\subsubsection{Effect of an appropriate $\mathrm{pH}$}

$\mathrm{PH}$ of a solution has a significant role on the formation of the metal complexes and subsequently on the preconcentration process. To ensure that the complex synthesis is carrying on in the best condition of $\mathrm{pH}$ the parameter of $\mathrm{pH}$ was analysed. This analysis was done in the same way as the previous steps by one-factor-at-a-time method. In this process the effect of $\mathrm{pH}$ on the quantity of extraction has been analysed in 2, 4, 6, 8, 10, and $12 \mathrm{pHs}$. Moreover, the other optimal parameters in extraction were taken into the regard. The obtained results from the $\mathrm{pH}$ effect is shown in the Figure (Fig. 6)As it is shown in the mentioned figure in the $\mathrm{pH}$ of 8 , the largest quantity of samarium was obtained from water samples. Therefore, $\mathrm{pH}-8$ was chosen for the next experiments as the optimal $\mathrm{pH}$ rate.

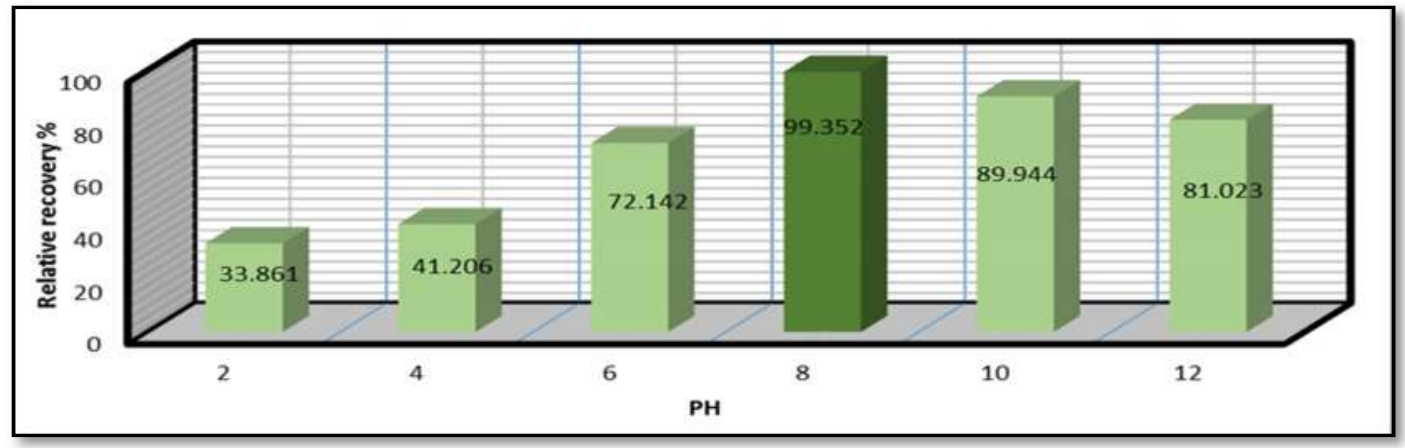

Figure 6. Effect of $\mathrm{PH}$ on the extraction efficiency 


\subsubsection{PAN Volume Optimization}

In order to analyse the effect of ligand volume, pan ligand solution 0.0634 molar was taken and assessed in the volumes of $60,80,100,120,140$, and 160 microliters to analyse its impact on the quantity of the extraction. Analysis of ligand volume impact was performed in the range of 60-160 microliters. The results revealed that the volume of 120 microliters of ligand with the concentration of $3 / 045 \times 10^{-4}$ has shown in the Figure (Fig. 7) best ratio of recovery by ICP-MS instrument and therefore, this amount was chosen for use.

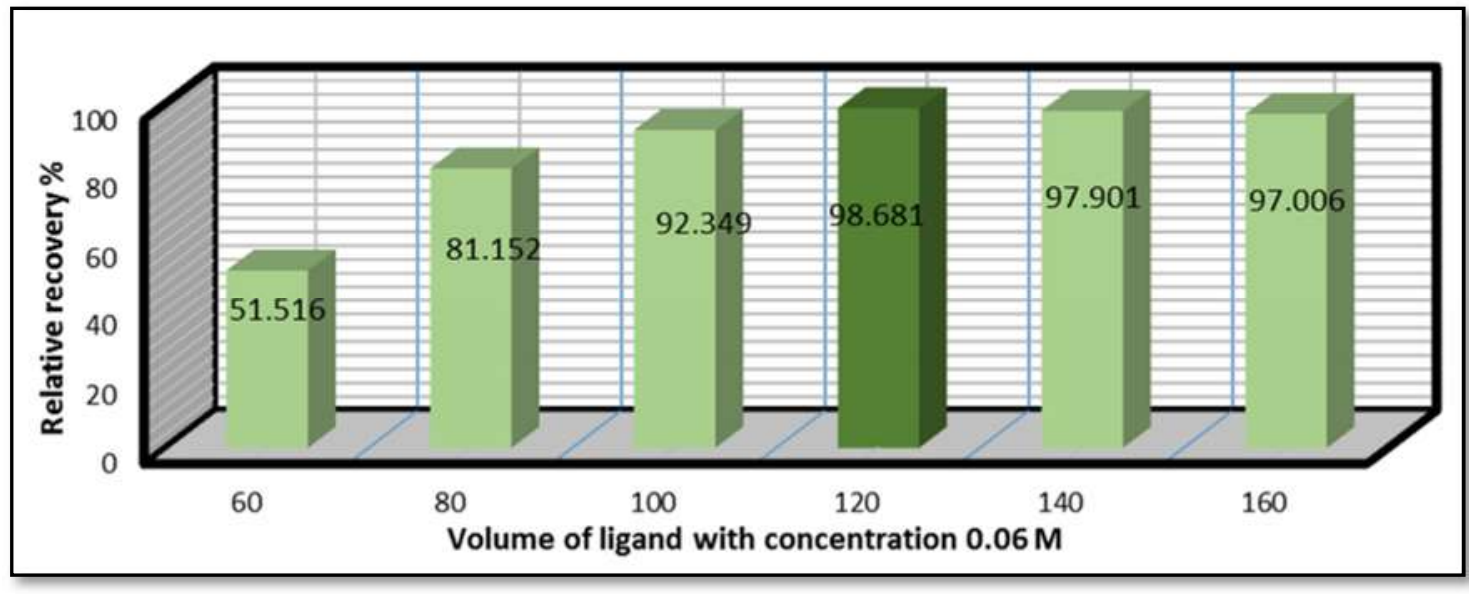

Figure 7. Effect of PAN on the extraction efficiency

\subsubsection{Optimization of Salt concentration}

The effect of salt increase on the extraction quantity has been surveyed by changing the salt $(\mathrm{NaCl})$ concentrationin the range of 1-3 M. concentration of $2.5 \mathrm{M}$ has shown in the Figure (Fig. 8) best ratio of the recovery by the ICP-MS instrument and for this reason the mentioned concentration was chosen for use in the next steps.

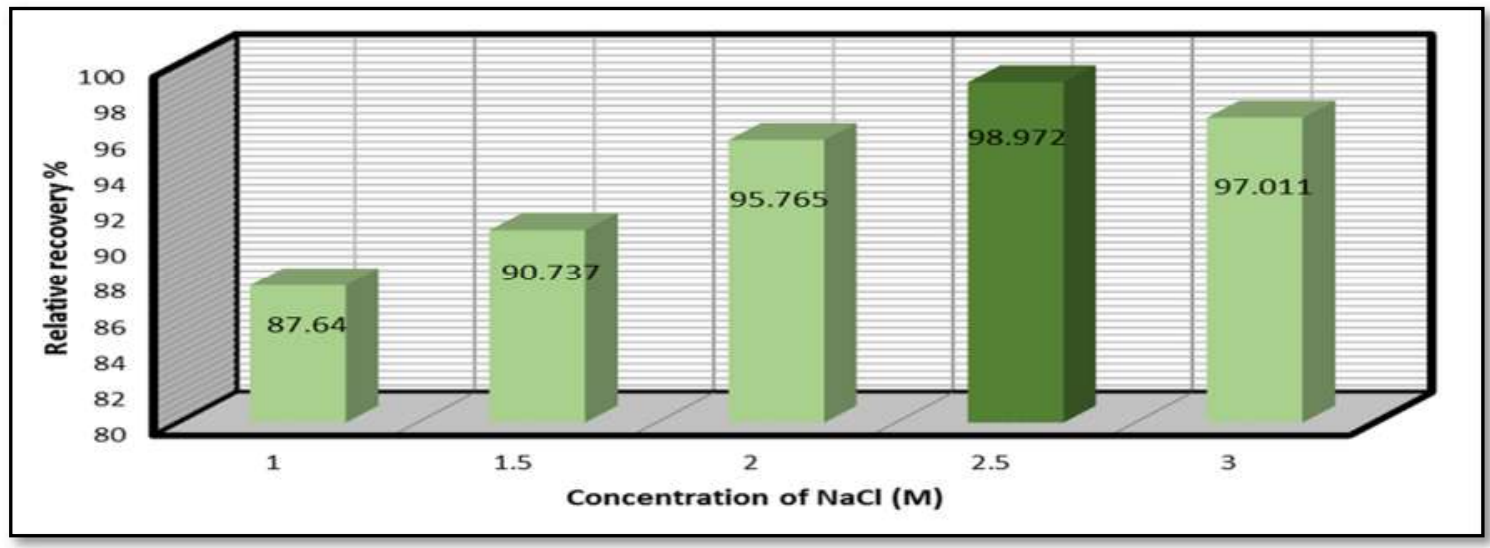

Figure8. Effect of concentration of $\mathrm{NaCl}$ on the extraction efficiency

\subsubsection{The Effect of Extraction Time Period}

In the mentioned procedure, time of extraction is defined as the time period after the sample injection into the cell and before the flotation process. In this phase the optimal experiment conditions were carried on as the following: $140 \mu \mathrm{L}$ 1-Dodecanol, $1.2 \mathrm{~mL}$ Tetrahydrofuran, $\mathrm{pH}=8.0$, $3.045 \times 10^{-4} \mathrm{~mol} \mathrm{~L}^{-1} \mathrm{PAN}$, and $2.5 \mathrm{~mol} \mathrm{~L}^{-1} \mathrm{NaCl}$, and the effect of time period on the amount of extraction was also analysed according to these periods: 60, 120, 180, and 240 seconds. Based on the obtained results the ratio of the recovery variation to the time of extraction is not significant. Moreover, after the aeration of the solution the contact surface of water phase and extractant phase increases and accordingly, the analyte transfer from the water phase (sample) to the extractant solvent occurs very 
quickly. The balancing period happens very quickly due to the shortness of the extraction time. Time of extraction was considered 120 seconds(Fig. 9).

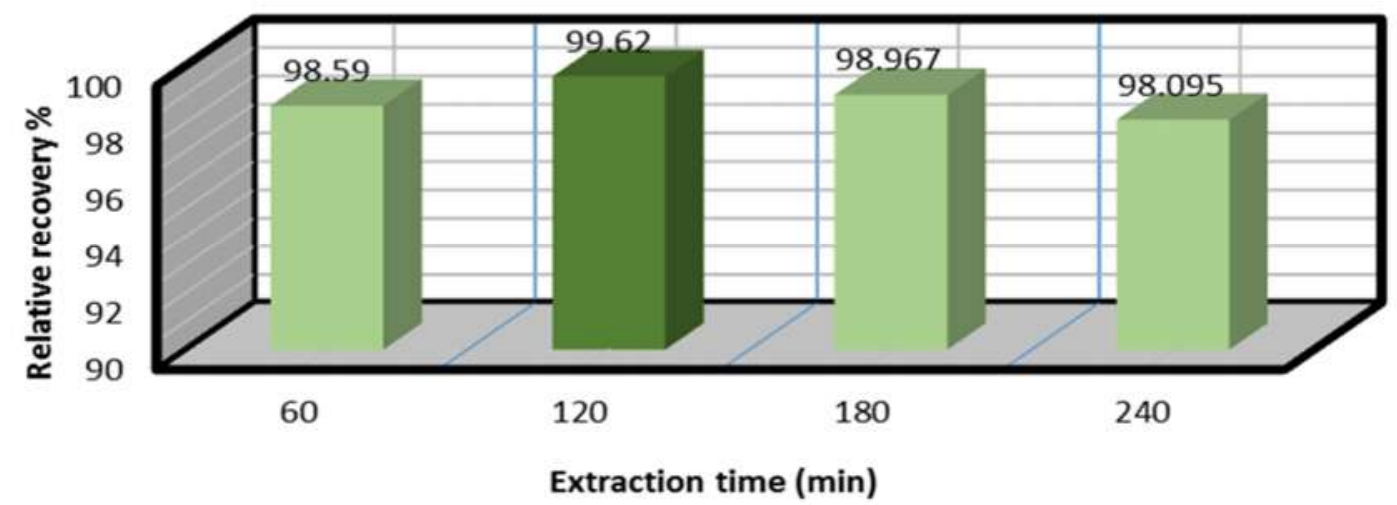

Figure9. Effect of extraction time on the extraction efficiency

\subsection{Real Sample}

To measure the quantity of samarium in the real samples based on optimal conditions, we did the extraction process three times without element increase and three times with $40 \mathrm{ppt}$ samarium increase. After that the percent recovery in Yazd mineral concentrate was determined which has shown good results, too (Table 2).

Table 2. Results of real sample of samarium under optimal conditions

\begin{tabular}{ccccc}
\hline Sample & Sm (ppt) & Spiked (ppt) & Extracted (ppt) & Recovery\% \\
\hline Mineral concentrate 1- Yazd & $9 / 121 \pm 0.647$ & 40 & $48 / 326 \pm 1 / 543$ & $91 \%$ \\
Mineral concentrate 2- Yazd & $7 / 997 \pm 1 / 731$ & 40 & $47 / 002 \pm 1.456$ & $92.21 \%$ \\
\hline
\end{tabular}

\subsection{Quantitative analysis}

The characteristics of calibration curve shown in Table 3. were obtained under optimized conditions. Linearity was observed in the range of $10-220 \mathrm{ng} \mathrm{L}^{-1}$. Correlation coefficient $\left(\mathrm{r}^{2}\right)$ was 0.9862 . The relative standard deviation (RSD, $n=7$ ) was calculated $2.1 \%$. The limit of detection (LOD) was 2.91 .

Table 3. Quantitative results of HLLME-FA and ICP-MS method for Sm

\begin{tabular}{|c|c|c|c|c|}
\hline Analyte & Linear range (ng/L) & $\mathrm{LOD}^{1}(\mathrm{ng} / \mathrm{L})$ & RSD $(\%)^{2}$ & $\mathbf{R}^{2}$ \\
\hline $\mathrm{Sm}$ & $10-220$ & 2.91 & 2.1 & 0.9862 \\
\hline
\end{tabular}

\section{Conclusion}

This paper describes the application of the HLLME-FA method combined with ICP-MS for the determination of amounts of samarium in Mineral concentrate samples. The method is precise, reproducible and linear over a wide range and requires small volumes of organic extractant. The new procedure of HLLME-FA does not need centrifugation to separate the organic phase. In this 
method, air flotation was used to break up the organic-in water emulsion and to finish the extraction process. The performance of this procedure in samarium extraction from different mineral samples with various matrices was good and no matrix effect was observed.

\section{References}

1. Ferenc.Szabadváry. Handbook of the Chemistry and Physics of the Rare Earths. Elsevier Science Publishers 1998; Vol. 11,pp. 52-62.

2. Dr. J.Andraos.; http://www.careerchem.com/NAMED/Elements-Discoverers.

3. M.Atanassova. Chemistry: Bulgarian Journal of Science Education 2015, Volume 24, p1.

4. R.B.Soorya, V.Bhadran, M.V.Vincy, B. Rajan. Indian J. Res. Found 2015, 4,p 19-25.

5. A.Jordens, Y.P.Cheng, K.E.Waters. A review of the beneficiation of rare earth element bearing minerals. Minerals Engineering 2013, 41, p97-114.

6. D.J.Procter, R.A.Flowers, T.Skrydstrup. Organic Synthesis Using Samarium Diiodide: A Practical Guide. Published by the Royal Society of Chemistry 2010, www.rsc.org, ISBN: 978-1-84755-110-8

7. N.Rosli. Low-lying excited energy states and structure of deformed nuclei. Dissertation (M.Sc.), Universiti Malaya, 2013.

8. C.Ekström, S.Ingelman, M.Olsmats, B.Wannberg. Nuclear Spins of Neutron-deficient Promethium, Samarium, Europium and Gadolinium Isotopes. Physica Scripta 1972, 6, p.p 4

9. G.Pagano, M.Guida, F.Tommasi, R.Oral., Health effects and toxicity mechanisms of rare earth elements. Ecotoxicology and Environmental Safety 2015, 115, p 40-48.

10. X.Xiao, L.Yong, D.Liu, H.Yang, Ch.Liang, X.Jia, Z.Liu, Y.Song. Effects of in utero exposure to lanthanum on neurological behavior in rat offspring. Neurotoxicology and Teratology 2020, 77,p.p 106854

11. P.Ratre, D.Kumar. Spectrophotometric Determination of Trace Amounts of Samarium in Environmental Samples. American International Journal of Research in Formal, Applied\&Natural Sciences 2013, 3, pp. 110-118. 12. A.Ikesue, Y.L.Aung. Ceramic laser materials. nature photonics 2008, 2,p 721 - 727

13. M.J.Weber. Chapter 35 Rare earth lasers. Handbook on the Physics and Chemistry of Rare Earths 1979; 4, P 275-315.

14. R.Floreza, H.A.Colorado, C.Giraldo, A.Alajoa. Preparation and characterization of Portland cement pastes with $\mathrm{Sm}_{2} \mathrm{O}_{3}$ microparticle additions for neutron shielding applications. Constr Build Mater 2018, 191, P 498-506. 15. R.R.Bhosal, A.Kumar, F.AlMomani, U.Ghosh, D.Dardor, Z.Bouabidi,M.Ali, Sh.Yousefi, A.AlNouss, M.S.Anis, M.H.Usmani,M.H.Ali, R.S.Azzam, A.Banu. Solar co-production of samarium and syngas via methanothermal reduction of samarium sesquioxide. Energy Conversion and Management 2016, 112, 413-422.

16. Sh.Aich, Crystal structure, microstructure and magnetic properties of rapidly solidified samarium-cobalt based alloys. Dissertation (phd), The University of Nebraska-Lincoln, 2005, UMI Microform 3186845

17. A.R.Jha. Rare Earth Materials: Properties and Applications. CRC Press., 2016, ISBN: 9781466564039, 1466564032 .

18. A.Raja, R.Nagaraj, K.Ramachandran, V.Sivasubramani, G.Annadurai, D.J.Daniel, P.Ramasamy. A facile synthesis, structural and triple-luminescence properties of a novel fluoroperovskite $\mathrm{RbCaF}_{3}: \mathrm{Sm}^{3+}$ phosphor for radiation dosimetry and orange-red LED applications. Materials Science and Engineering: B 2020, 255, p114531. 19. Q.Zhou, X.Zhong, X.Xie, X.Jia, B.Chen, N.Wang, L.Huang. Auto-thermal reforming of acetic acid for hydrogen production by ordered mesoporous Ni-xSm-Al-O catalysts: Effect of samarium promotion. Renewable Energy 2020, 145, Pages 2316-2326. 
20. C.Kukusamude, S.Kongsri., Method validation for determination of some rare-earth elements in rice using ICP-MS., Journal of Physics 2019, International Nuclear Science and Technology Conf.series $1285,012020$.

21. I.Wysocka. Determination of rare earth elements concentrations in natural waters-a review of ICP-MS measurement approaches. Talanta2021, 221, p 121636, https://doi.org/10.1016/j.talanta.2020.121636.

22. M.Hosseini, N.Dalalia, S.M.Nejad. A New Mode of Homogeneous Liquid-liquid Microextraction (HLLME) Based on IonicLiquids: In Situ Solvent Formation Microextraction (ISFME) for Determination of Lead. J. Chin. Chem. Soc 2012, 59,p 872-878.

23. S.M.Sorouraddin, M.A.Farajzadeh, T.Okhravi. A green solventless temperature-assistedhomogeneous liquid-liquid microextractionmethod based on 8-hydroxyquinolinesimultaneously as complexing agent andextractant for preconcentration of cobalt andnickel from water and fruit juice samples. International Journal of EnvironmentalAnalytical Chemistry 2019, 99, Pages 124-138.

24. M.A.Jeannot, A.Przyjazny, J.M.Kokosac. Single drop microextraction-Development, applications and future trends. Journal of Chromatography-A 2010, 1217, p2326-2336,DOI: 10.1016/j.chroma.2009.10.089 .

25. S.Habibi, S.Vieseh, A.Bashiri Far, A.Niazi , J. Iranian Chem. Res 2014, 7, p37-45.

26. S.A.M.Fathi, M.R.Yaftian. Journal of Colloid and Interface Science 2009, 334, p167-170 ,DOI: 10.1016 /j.jcis. 2009.02.071.

27. K.E.Rasmussen, S.P.Bjergaard,TrAC Trends in Analytical Chemistry 2004, 23, 1-10 , DOI: 10.1016 /S01659936 (04)00105-0.

28. Shayessteh Dadfarnia, Ali Mohammad Haji Shabani, Analytica Chimica Acta, 658 (2010) 107-119, DOI: 10.1016/j.aca.2009.11.022.

29. S.Kinaree, S.Chanthai , Chemical Papers 2014, 3, p342-351,DOI: 10.2478/s11696-013-0459-9.

30. M. H.Hosseinia, M.Rezaeea, S.Akbarianb, F.Mizanic, M.R. Pourjavida, M.Arabieha ,Analytica Chimica Acta 2013,762, p 54-60,DOI:10.1016/j.aca.2012.10.030.

31. M.H.Hosseinia, M.Rezaeea, H.A.Mashayekhib, S.Akbarianc, F.Mizanid, M.R.Pourjavida, Journal of Chromatography A 2012, 1265, p52- 56, DOI:10.1016/j.chroma.2012.09.099.

32. Sh.Chen, Sh.Zhu, D.Lu. Solidified Floating Organic Drop Microextraction for the Determination of Trace Dy and Y by Electrothermal Vaporization Inductively Coupled Plasma Mass Spectrometry. Microchim Acta 2013, $180,1479-1486$. 